\title{
A Randomized Trial Comparing the Diagnostic Yield of Rigid and Semirigid Thoracoscopy in Undiagnosed Pleural Effusions
}

\author{
Sahajal Dhooria MD DM, Navneet Singh MD DM, Ashutosh N Aggarwal MD DM, \\ Dheeraj Gupta MD DM, and Ritesh Agarwal MD DM
}

\begin{abstract}
BACKGROUND: Thoracoscopic pleural biopsy increases the diagnostic yield of pleural effusions undiagnosed after thoracentesis and is superior to closed pleural biopsy. Medical thoracoscopy can be performed using the rigid thoracoscope or the semirigid thoracoscope (pleuroscope). In this randomized trial, we compare the efficacy and safety of the 2 thoracoscopes. METHODS: Subjects with undiagnosed exudative pleural effusions were randomly assigned to undergo pleural biopsy with either the rigid or the semirigid thoracoscope. The primary outcome was the diagnostic yield of the procedure, while the secondary outcomes were requirement of sedative/analgesic agents, scar size, biopsy sample size, and the operator's view of the procedure. RESULTS: Of the 145 screened subjects with exudative pleural effusions, 90 were randomized to undergo thoracoscopy with the 2 thoracoscopes $(n=45$ each). The diagnostic yield of rigid thoracoscopy was superior to semirigid thoracoscopy $(97.8 \%$ vs $73.3 \%, P=.002)$ on an intention-to-treat analysis but was similar $(100 \%$ vs $94.3 \%, P=.18$ ) in those with successful biopsy. The requirement of sedative/analgesic agents was higher in the rigid thoracoscopy arm. The scar size was slightly larger (mean \pm SD, $23.1 \pm 4$ vs $18.7 \pm 3.2 \mathrm{~mm}, P=.0001$ ), whereas the biopsy sample size was distinctly larger in the rigid arm (mean $\pm \mathrm{SD}, 13.9 \pm 4.4 \mathrm{vs} 4.4 \pm 1.4 \mathrm{~mm}, P=.001)$. The operator-rated visual analog scale score for the ease of taking a biopsy sample was significantly higher with the rigid instrument (mean \pm SD, visual analog scale $86 \pm 12$ vs $79 \pm 12 \mathrm{~mm}, P=.01$ ), while the quality of image was superior in the semirigid arm (mean $\pm \mathrm{SD}$, visual analog scale $88 \pm 7$ vs $92 \pm 5 \mathrm{~mm}, P=.002$ ). The number of complications were similar in the 2 groups. CONCLUSIONS: Rigid thoracoscopy was found to be superior to semirigid thoracoscopy overall, but the diagnostic yield was similar if pleural biopsy could be successfully performed. Due to the small sample size, a larger study is required to define the usefulness and choice between the 2 procedures. (ClinicalTrials.gov registration NCT01726556) Key words: thoracoscopy; semirigid; pleural effusion; lung cancer; tuberculosis. [Respir Care 2014;59(5):756-764. (C) 2014 Daedalus Enterprises]
\end{abstract}

\section{Introduction}

About $20-40 \%$ of patients with pleural effusions remain undiagnosed despite pleural fluid analysis and closed pleural biopsy. ${ }^{1-5}$ Medical thoracoscopy increases the diagnostic yield in these cases. ${ }^{6}$ The sensitivity of thoracos-

The authors are affiliated with the Department of Pulmonary Medicine, Postgraduate Institute of Medical Education and Research, Chandigarh, India.

The authors have disclosed no conflicts of interest. copy ranges from $80 \%$ to $100 \%$ in the diagnosis of pleural effusions. ${ }^{7}$ Rigid thoracoscopy, with or without video assistance has traditionally been the procedure of choice. ${ }^{8,9}$ A semirigid thoracoscope (pleuroscope) combining the fea-

\footnotetext{
Correspondence: Ritesh Agarwal MD DM, Associate Professor, Department of Pulmonary Medicine, Postgraduate Institute of Medical Education and Research, Sector-12, Chandigarh 160012, India. E-mail: riteshpgi@gmail.com
}

DOI: $10.4187 /$ respcare.02738 
tures of rigid thoracoscope and flexible bronchoscope has been available since its first report in $1998 .{ }^{10}$ Two recent systematic reviews have concluded that the semirigid pleuroscope is a safe, easy-to-handle, and accurate tool in the diagnosis of pleural effusions of undetermined origin. ${ }^{11,12}$ Another retrospective study ${ }^{13}$ found comparable histologic yields of the rigid and the semirigid thoracoscopes. There is only one published randomized trial ${ }^{14}$ comparing the yield of the 2 instruments wherein the authors found comparable diagnostic accuracy of the 2 instruments despite the smaller biopsy size obtained with the semirigid device.

We hypothesized that the yield with rigid thoracoscopy would be better than with semirigid thoracoscopy because of the larger biopsy sample size with the former and the fact that the rigid thoracoscope allows better maneuverability in patients with adhesions. In this randomized trial we compare the efficacy and safety of RIgid versus SEmirigid (RISE Trial) thoracoscopy in undiagnosed exudated pleural effusions.

\section{Methods}

This was a prospective study conducted between May 2011 and October 2012 in the Department of Pulmonary Medicine, Postgraduate Institute of Medical Education and Research, a tertiary care referral center. The protocol was approved by the Institute Ethics Committee, and written informed consent was obtained from all subjects.

\section{Subjects}

Subjects were included in the study if they met the following criteria: (1) age $\geq 12$ years, and (2) presence of exudative pleural effusion, as determined by the criteria detailed by Light et al ${ }^{15}$ where a specific diagnosis was not obtained after 2 cytological and/or microbiological examinations. Closed pleural biopsy is not routinely performed at our center. Subjects with any of the following conditions were excluded from the study: $\mathrm{P}_{\mathrm{aO}_{2}} / \mathrm{F}_{\mathrm{IO}_{2}}<300$; hemodynamic instability; myocardial infarction or unstable angina in the last $6 \mathrm{wk}$; lack of pleural space due to adhesions; uncorrected coagulopathy; and failure to provide informed consent. We also excluded subjects with pleural fluid adenosine deaminase levels of $>70$ units/L and a clinical picture consistent with the diagnosis of tuberculous pleural effusion. All subjects underwent complete blood count, liver and renal function tests, coagulation profile determination, and an electrocardiogram. A computed tomography (CT) scan of the chest was obtained in subjects where a chest radiograph showed significant parenchymal abnormality or loculated effusion. The effusion was categorized as small (less than one-third of hemithorax), moderate (one-third to two-thirds of hemithorax), large (more than two-thirds of hemithorax), and massive

\section{QUICK LOOK}

\section{Current knowledge}

Pleural effusions remain undiagnosed in $\sim 20-40 \%$ of patients despite pleural fluid analysis and closed pleural biopsy. Medical thoracoscopy increases the diagnostic yield in these cases.

\section{What this paper contributes to our knowledge}

Rigid thoracoscopy was found to be superior to semirigid thoracoscopy overall, but the diagnostic yield was similar once a pleural biopsy could be successfully performed. A larger study is required to define the usefulness and clinician satisfaction between the 2 procedures.

(unilateral opaque hemithorax with contralateral mediastinal shift). A chest ultrasound was performed in selected subjects to exclude significant pleural loculations because most of the subjects presented late at our center, with many of them already receiving treatment including antibiotic and/or antituberculosis therapy.

\section{Randomization}

The subjects were randomly assigned to either the rigid thoracoscopy arm (outer diameter $10 \mathrm{~mm}$, working channel 5 mm; catalog no 8912.402, Richard Wolf, Knittlingen, Germany) or the semirigid thoracoscopy arm (outer diameter $7 \mathrm{~mm}$, working channel $2.8 \mathrm{~mm}$; LTF-160, Olympus Medical Systems, Tokyo, Japan). The randomization sequence was computer-generated, and the assignments were placed in opaque sealed envelopes. Each subject's assignment to a particular group was made sequentially. Blinding of treatment allocation was not possible. If a successful pleural examination could not be performed with the semirigid instrument, the rigid device was subsequently used.

\section{Procedure}

Thoracoscopy was performed in the bronchoscopy suite on a spontaneously breathing subject (fasting for $8 \mathrm{~h}$ ) under conscious sedation (using midazolam, pentazocine, and tramadol) observing complete aseptic precautions. Blood pressure was monitored every $10 \mathrm{~min}$, whereas oxygen saturation, heart rate, and rhythm were monitored continuously. Supplemental oxygen was administered via airentrainment mask. The operators were consultant pulmonologists or pulmonary fellows with 2.5 years of training and having assisted in at least 25 procedures under the direct supervision of one of the consultants. The consul- 
tants were equally trained in both rigid and semirigid thoracoscopy.

A single entry site was selected in the fourth or fifth intercostal space along the midaxillary line with the subject in the lateral decubitus position and involved side upward. The site was infiltrated with $2 \%$ lidocaine, and 1to 3 -cm skin incision was made. A blunt dissection was used to enter the pleural space; the incision was extended if required. The trocar supplied with the respective thoracoscopes (rigid thoracoscope: trocar sleeve with magnetic ball valve [catalog no. 8923.123, Richard Wolf] and trocar with blunt conical tip [catalog no. 8923.103, Richard Wolf]; semirigid thoracoscope: flexible trocar [MAJ-1058, Olympus Medical Systems]) was inserted followed by introduction of the thoracoscope. Pleural fluid was aspirated while air was allowed to enter the pleural space. The parietal, visceral, and diaphragmatic pleura were inspected and biopsies (6-8 with semirigid thoracoscope and 2-4 with rigid thoracoscope) were performed under direct vision in all suspect areas of the parietal pleura. Biopsies were performed using the respective biopsy forceps (rigid thoracoscope: catalog no. 8393.09135, Richard Wolf, $5 \mathrm{~mm}$ diameter; semirigid thoracoscope FB-55CR, Olympus Medical Systems, $2 \mathrm{~mm}$ diameter).

If there were fibrous adhesions that precluded biopsy with the semirigid device, subjects were crossed over to the rigid thoracoscopy arm, and adhesiolysis was performed followed by pleural biopsy. If an adequate pleural space could not be created even with the rigid scope, the procedure was stopped. A 24-28 French intercostal drainage tube was inserted before wound closure to evacuate air and fluid. If the thoracoscopic findings suggested malignancy (variable sized nodules), talc poudrage was performed during the procedure or was performed later by instilling talc slurry (or iodopovidone) through the chest tube. Chest radiographs were obtained $3 \mathrm{~h}$ after the procedure. The chest tube was removed only once the drainage decreased to $<50 \mathrm{~mL} / \mathrm{d}$ for 2 consecutive days and the effusion was nonpurulent.

\section{Outcome}

We recorded the clinical history, pleural fluid examination findings, and thoracoscopic findings on a standard data entry sheet. The primary outcome was the diagnostic yield of the procedure. A successful procedure was defined as (1) pleural biopsy yielding a definite histopathology or microbiological etiology or (2) histopathological findings (nonspecific pleuritis) consistent with subsequent clinical course and response to treatment. The primary outcome is reported on an intention-to-treat (ITT) basis; that is, the results are reported based on the initial treatment assigned (semirigid or rigid thoracoscopy) and not on the treatment eventually received. Subjects crossed from semirigid to rigid thoracoscopy were considered as failures of the semirigid arm irrespective of results with rigid thoracoscopy. We also calculated the diagnostic yield in the 2 arms in subjects who underwent a successful biopsy. The secondary outcomes were the requirement of sedative/ analgesic agents, scar size (maximal length), biopsy sample size (longest axis length), and the operator's view of the procedure. The operators recorded the quality of the image, ease of maneuvering, ease of obtaining a biopsy sample, and the expectation that the biopsy sample will reveal a definitive histological diagnosis on the visual analog scale from 0 to 100 . The duration of intercostal tube drainage and complications were also recorded. The complications were classified as major (empyema, major hemorrhage [drop in hemoglobin by $1 \mathrm{~g} / \mathrm{dL}$ or requiring blood transfusion], persistent air leak of $>3 \mathrm{~d}$, and re-expansion pulmonary edema) and minor (subcutaneous emphysema, operative site infection, noninfective fever, and minor hemorrhage), as previously described. ${ }^{16}$ All subjects were followed up for at least 3 months following the procedure.

\section{Statistical Analysis}

Data are expressed as the mean $\pm \mathrm{SD}$ or percentage. Differences in continuous variables between the 2 groups were compared using the Student $t$ test (or Mann-Whitney $U$ test), whereas differences in categorical data were compared using the chi-square test (or Fisher exact test). A $P$ value of $<.05$ was considered statistically significant.

\section{Results}

During the study period, 145 subjects with exudative pleural effusions were managed; 90 subjects (mean \pm SD age, $51.5 \pm 14.3$ years; 62 men [68.9\%]) were randomized to undergo thoracoscopy with subjects equally distributed between the 2 arms (Fig. 1). The baseline characteristics of the subjects are shown in Table 1. There was no significant difference in any of these characteristics. Dyspnea, chest pain, cough, and fever were the most common symptoms, in order of frequency. The effusion was large to massive in $35.5 \%$ of subjects and bilateral in 8 subjects $(8.9 \%)$. In the semirigid arm, the thoracoscope could not be maneuvered in 10 subjects because of adhesions. Seven subjects were crossed over to the rigid thoracoscopy arm whereas in 3 subjects the procedure was abandoned due to absolute lack of pleural space. Of the 7 subjects who crossed over, rigid thoracoscopy and biopsy could be performed in 3 subjects after adhesiolysis, whereas in the remaining 4 subjects biopsy could not be performed even with the rigid thoracoscope due to extensive adhesions. In the rigid thoracoscopy arm, the thoracoscope could not be manipulated in the pleural cavity in one subject, and the procedure was abandoned (see Fig. 1). Thus the procedure could be com- 


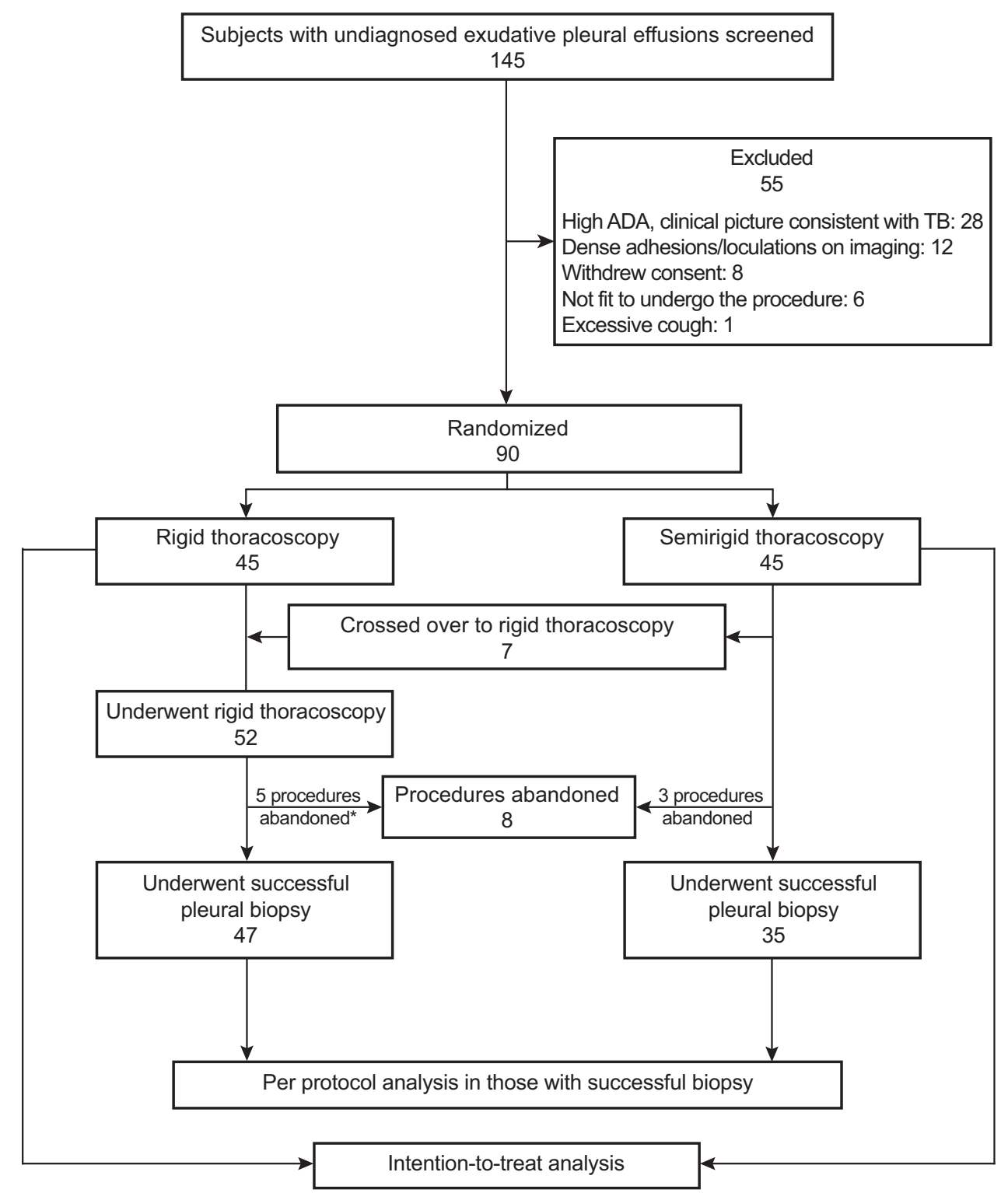

Fig. 1. CONSORT flow diagram depicting the study protocol and the participant inclusion process, * Of the 5 subjects, 4 crossed over from the semirigid arm. ADA = adenosine deaminase. TB = tuberculosis.

pleted in 82 of the 90 randomized subjects. Although higher in the semirigid group, the number of procedures interrupted (10 of 45 subjects in the semirigid group, 5 of 52 subjects in the rigid group, $P=.09$ ) were not statistically different between the 2 groups. Of the 8 failed cases, loculations were observed by any method (ultrasound, chest radiograph, or chest CT scan) in 4 cases, while loculations were observed in 20 of the 82 subjects with successful biopsy $(P=.8)$. The procedures were performed primarily by fellows under direct supervision of the consultants.

The diagnostic yield of rigid thoracoscopy (44 of 45 subjects, $97.8 \%$ ) was superior to that of semirigid thoracoscopy (33 of 45 subjects, $73.3 \%$ ) on an ITT analysis $(P=.002)$. However, the yield was similar when only those in whom biopsy was performed were considered $(P=.18)$ (Table 2). The requirement of sedative/analgesic agents was higher in the rigid thoracoscopy arm (see Table 2). The scar size was slightly larger (mean size 23.1 vs $18.7 \mathrm{~mm}$ ) in the rigid versus the semirigid arm (see Table 2); however, the biopsy sample size was significantly larger in the rigid thoracoscopy group (median $14 \mathrm{vs} 4 \mathrm{~mm}$ ). The visual analog scale for ease of obtaining a biopsy sample was significantly higher in the rigid $\operatorname{arm}(P=.01)$, whereas that for the quality of image was significantly higher in the semirigid arm $(P=.002)$ (see Table 2$)$. The duration of the procedure was similar in the 2 groups.

The thoracoscopic and histopathological findings are shown in Table 3. Adhesions and nodules were found in 


\section{Thoracoscopy in Undiagnosed Pleural Effusions}

Table 1. Baseline Characteristics of the Study Population

\begin{tabular}{|c|c|c|c|c|}
\hline Characteristics & $\begin{array}{l}\text { Rigid Thoracoscopy } \\
\qquad(n=52)\end{array}$ & $\begin{array}{l}\text { Semirigid Thoracoscopy } \\
\qquad(n=45)\end{array}$ & $\begin{array}{c}\text { Total } \\
(n=90)\end{array}$ & $P$ \\
\hline Age $(y)$ & $54.2 \pm 14.9$ & $48.8 \pm 13.3$ & $51.5 \pm 14.3$ & .08 \\
\hline Sex (male/female) & $31: 14$ & $31: 14$ & $62: 28$ & $>.99$ \\
\hline History of tobacco smoking, $n(\%)$ & $9(20.0)$ & $8(17.8)$ & $17(18.9)$ & $>.99$ \\
\hline Duration of symptoms (d) & $26.9 \pm 10.2$ & $27.9 \pm 13.1$ & $27.5 \pm 11.7$ & .68 \\
\hline \multicolumn{5}{|l|}{ Comorbidities } \\
\hline Hypertension & $14(31.1)$ & $17(37.8)$ & $31(34.4)$ & .66 \\
\hline Diabetes mellitus & $13(28.9)$ & $9(20.0)$ & $22(24.4)$ & .46 \\
\hline Chronic kidney disease & 7 (15.6) & $10(22.2)$ & $17(18.9)$ & .59 \\
\hline \multicolumn{5}{|l|}{ Preprocedure diagnosis } \\
\hline Malignancy & $22(48.9)$ & $18(40.0)$ & $40(44.4)$ & .53 \\
\hline Tuberculosis & $23(51.1)$ & $27(60.0)$ & $50(55.6)$ & \\
\hline \multicolumn{5}{|l|}{ Pleural fluid investigations } \\
\hline Total leukocyte count (cells $/ \mu \mathrm{L}$ ) & $1040 \pm 1852$ & $812 \pm 926$ & $926 \pm 1461$ & .46 \\
\hline Protein $(\mathrm{g} / \mathrm{dL})$ & $4.63 \pm 1.15$ & $4.98 \pm 1.26$ & $4.81 \pm 1.21$ & .16 \\
\hline Glucose (mg/dL) & $104.6 \pm 67.9$ & $99.2 \pm 34.5$ & $101.9 \pm 53.7$ & .63 \\
\hline Adenosine deaminase (units/L) & $26.9 \pm 18.9$ & $30.3 \pm 18$ & $28.7 \pm 18.4$ & .39 \\
\hline \multicolumn{5}{|l|}{ Amount of pleural effusion } \\
\hline Small & 7 (15.6) & $9(20.0)$ & $16(17.8)$ & .58 \\
\hline Moderate & $19(42.4)$ & $23(51.1)$ & $42(46.7)$ & .40 \\
\hline Large & $4(8.9)$ & $6(13.3)$ & $10(11.1)$ & .50 \\
\hline Massive & $15(33.3)$ & $7(15.6)$ & $22(24.4)$ & .09 \\
\hline \multicolumn{5}{|l|}{ Presence of loculations, $n / N(\%)$} \\
\hline Chest radiograph & 9/45 (20.0) & $6 / 45(13.3)$ & $15 / 90(16.7)$ & .57 \\
\hline Chest CT scan & $9 / 37(24.3)$ & $10 / 35(28.6)$ & $19 / 72(26.4)$ & .79 \\
\hline Thoracic ultrasound & 4/11 (31.4) & $5 / 24(20.8)$ & $9 / 35(25.7)$ & .42 \\
\hline By any technique & $11 / 45(24.4)$ & $13 / 45(28.9)$ & $24 / 90(26.7)$ & .81 \\
\hline
\end{tabular}

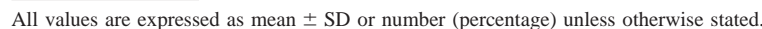

Table 2. Primary and Secondary Outcomes of the Study

\begin{tabular}{|c|c|c|c|c|}
\hline Outcomes & Rigid Thoracoscopy & Semirigid Thoracoscopy & Total & $P$ \\
\hline \multicolumn{5}{|l|}{ Primary } \\
\hline \multicolumn{5}{|l|}{ Diagnostic yield } \\
\hline ITT & $44 / 45(97.8)$ & $33 / 45(73.3)$ & & .002 \\
\hline In those with successful biopsy & $47 / 47(100)$ & $33 / 35(94.3)$ & & .18 \\
\hline Secondary & $(N=44)$ & $(N=35)$ & & \\
\hline \multicolumn{5}{|l|}{ Doses of sedatives/analgesics (mg) } \\
\hline Midazolam & $5.1 \pm 2.3$ & $3.9 \pm 1.3$ & $4.5 \pm 1.9$ & .009 \\
\hline Pentazocine & $45 \pm 16.5$ & $39 \pm 13.2$ & $42.3 \pm 15.3$ & .08 \\
\hline Tramadol & $68.8 \pm 30.6$ & $50.1 \pm 31.9$ & $60.5 \pm 32.3$ & .01 \\
\hline Scar size $(\mathrm{mm})$ & $23.1 \pm 4$ & $18.7 \pm 3.2$ & $21.2 \pm 4.3$ & .0001 \\
\hline Biopsy sample size (mm) & $13.9 \pm 4.4$ & $4.4 \pm 1.4$ & $9.2 \pm 5.8$ & .001 \\
\hline Duration of procedure (min) & $58.6 \pm 13.9$ & $53.4 \pm 10.8$ & $56.3 \pm 12.8$ & .07 \\
\hline Duration of postprocedure intercostal tube drainage (d) & $5.6 \pm 5.8$ & $5.5 \pm 7.5$ & $5.6 \pm 6.6$ & .95 \\
\hline \multicolumn{5}{|l|}{ Operator-rated characteristics on visual analog scale $(0-100 \mathrm{~mm})$} \\
\hline Quality of image & $88 \pm 7$ & $92 \pm 5$ & & .002 \\
\hline Ease of maneuvering & $85 \pm 14$ & $84 \pm 12$ & & .87 \\
\hline Ease of taking a biopsy & $86 \pm 12$ & $79 \pm 12$ & & .01 \\
\hline Expectation that biopsy will reveal a definitive histological diagnosis & $86 \pm 17$ & $83 \pm 19$ & & .41 \\
\hline
\end{tabular}

All values are expressed as mean $\pm \mathrm{SD}$ or $n(\%)$ unless otherwise stated. All secondary outcomes are reported after excluding the procedures that were either converted or abandoned. 
Table 3. Thoracoscopic Findings and Histopathological Diagnosis of Study Subjects

\begin{tabular}{|c|c|c|c|c|}
\hline Variables & Rigid Thoracoscopy & Semirigid Thoracoscopy & Total & $P$ \\
\hline \multicolumn{5}{|l|}{ Thoracoscopic findings } \\
\hline Presence of adhesions & $28 / 45(62.2)$ & 25/45 (55.6) & $53 / 90(58.9)$ & .67 \\
\hline Few & $12 / 28(42.9)$ & $12 / 25(48.0)$ & $24 / 53(45.3)$ & .79 \\
\hline Extensive & $16 / 28(57.1)$ & $13 / 25(52.0)$ & $29 / 53(54.7)$ & \\
\hline Thin & $7 / 28(25.0)$ & $10 / 25(40.0)$ & $17 / 53(32.1)$ & .24 \\
\hline Thick & $11 / 28(39.3)$ & $9 / 25(36.0)$ & $20 / 53(37.7)$ & .81 \\
\hline Both & $10 / 28(35.7)$ & $6 / 25(24.0)$ & $16 / 53(30.2)$ & .35 \\
\hline Presence of nodules & $31 / 47(66.0)$ & 23/35 (65.7) & $54 / 82(65.9)$ & $>.99$ \\
\hline Focal & $15 / 31(48.4)$ & $11 / 23(47.8)$ & $26 / 54(48.1)$ & $>.99$ \\
\hline Diffuse & 16/31 (51.6) & $12 / 23(52.2)$ & $28 / 54(51.9)$ & \\
\hline Uniformly sized & $13 / 31(41.9)$ & $12 / 23(51.2)$ & $25 / 54(46.3)$ & .58 \\
\hline Variably sized & $18 / 31(58.1)$ & $11 / 23(47.8)$ & $29 / 54(53.7)$ & \\
\hline Histopathological diagnosis & $(N=47)$ & $(N=35)$ & $(N=82)$ & \\
\hline Malignancy & $19(40.4)$ & $7(20)$ & $26(31.7)$ & .08 \\
\hline Tuberculosis & $12(25.5)$ & $9(25.7)$ & $21(25.6)$ & .98 \\
\hline Nonspecific inflammation/fibrinous pleuritis & $15(31.9)$ & $17(48.6)$ & $32(39.0)$ & .49 \\
\hline Sarcoidosis & $1(2.1)$ & 0 & $1(1.2)$ & \\
\hline Aspergillosis & 0 & $1(2.9)$ & $1(1.2)$ & \\
\hline Rheumatoid nodule & 0 & $1(2.9)$ & $1(1.2)$ & \\
\hline
\end{tabular}

All values are expressed as $n / N(\%)$ unless otherwise stated.

Table 4. Association of Gross Thoracoscopic Findings and Probability of Histological Diagnosis

\begin{tabular}{lcc}
\hline \hline Thoracoscopic Findings & $\begin{array}{c}\text { Histological } \\
\text { Diagnosis }\end{array}$ & $\begin{array}{c}\text { Odds Ratio } \\
(95 \% \text { CI })\end{array}$ \\
\hline $\begin{array}{l}\text { Presence of nodules } \\
\text { Size of nodules } \\
\text { Presence of variable } \\
\text { sized nodules }\end{array}$ & Definitive diagnosis* & $6.7(2.4-18.3)$ \\
$\quad \begin{array}{l}\text { Presence of uniform } \\
\text { sized nodules }\end{array}$ & Tuberculosis & $4.9(1.7-14.2)$ \\
$\begin{array}{l}\text { Distribution of nodules } \\
\text { Diffuse nodules } \\
\text { Diffuse nodules }\end{array}$ & $\begin{array}{c}\text { Malignancy } \\
\text { Tuberculosis }\end{array}$ & $2.1(0.8-5.6)$ \\
\end{tabular}

* A definitive diagnosis implies, for example, a histological diagnosis of malignancy or tuberculosis, and excludes nonspecific inflammation or fibrinous pleuritis.

53 and 54 subjects, respectively, on thoracoscopic examination (Table 3). The presence of nodules predicts high odds for obtaining a definitive histological diagnosis on pleural biopsy specimens (Table 4). The presence of variably sized nodules suggests higher odds for malignancy, whereas the odds for tuberculosis are higher with uniformly sized nodules. Diffuse distribution of nodules predicted the diagnosis of tuberculosis (Table 4).

The most common definitive histological diagnosis made from pleural biopsy was malignancy followed by tuberculosis (Table 3). One subject with an established diagnosis of sarcoidosis received a diagnosis of sarcoidosis-related pleural effusion based on the histopathology finding of compact granulomas and resolution of the effusion with glucocorticoids. Another subject with a known case of allergic bronchopulmonary aspergillosis was found to have pleural effusion secondary to allergic bronchopulmonary aspergillosis; she was treated with steroids and voriconazole and did not have recurrence of the pleural effusion. One subject with a known diagnosis of rheumatoid arthritis was found to have rheumatoid pleurisy, which improved after treatment with steroids. Pleural biopsy samples from 32 subjects showed nonspecific inflammation or fibrinous pleuritis, and the follow-up data for these subjects is shown in Table 5. In 2 of the 32 subjects, a final diagnosis of tuberculous pleural effusion was made (both in the semirigid arm), which was considered to be a failure of the procedure (Table 5). In one of these subjects, the diagnosis was made on the basis of demonstration of necrotizing granulomatous inflammation on transbronchial lung biopsy sample. The other subject was given empiric antituberculosis treatment (in view of a positive tuberculin skin test result and nonresponse to antibiotic therapy) and showed a response. A pleural biopsy sample could not be obtained in a total of 8 subjects. Six of these subjects received diagnoses of inadequately treated parapneumonic effusion and were given prolonged antibiotic therapy. One subject with chronic kidney disease was given empiric antituberculosis therapy. Another subject received a diagnosis of tuberculous pleural effusion based on positive findings on sputum mycobacterial cultures. 
Table 5. Follow-up of 32 Subjects With Nonspecific Inflammation/Fibrinous Pleuritis

\begin{tabular}{|c|c|c|}
\hline Characteristics & $\begin{array}{l}\text { Patients }(n) / \text { Duration of } \\
\text { Follow-Up (mo)* }\end{array}$ & Follow-Up \\
\hline Inadequately Treated Parapneumonic Effusion & $11 / 10-14$ & $\begin{array}{l}\text { Antituberculosis therapy was stopped; subjects were treated with } \\
\text { prolonged course of broad-spectrum antibiotics }\end{array}$ \\
\hline Uremic pleuritis & $9 / 8-12$ & $\begin{array}{l}\text { Given renal replacement therapy; pleural effusion decreased in } \\
\text { all these subjects with dialysis; } 5 \text { subjects underwent renal transplantation }\end{array}$ \\
\hline Idiopathic pleuritis & $10 / 10-12$ & $\begin{array}{l}\text { All treatment stopped after biopsy; follow-up showed no recurrence } \\
\text { of effusion }\end{array}$ \\
\hline Tuberculous pleural effusion & $2 / 4-6$ & $\begin{array}{l}\text { Lack of response to antibiotics and response to antituberculosis therapy; } \\
\text { transbronchial lung biopsy revealing necrotic granulomas in one subject }\end{array}$ \\
\hline
\end{tabular}

Table 6. Complications of Rigid and Semirigid Thoracoscopy

\begin{tabular}{|c|c|c|c|c|}
\hline Complications & $\begin{array}{c}\text { Rigid } \\
\text { Thoracoscopy }\end{array}$ & $\begin{array}{l}\text { Semirigid } \\
\text { Thoracoscopy }\end{array}$ & Total & $P$ \\
\hline Any & 16 & 9 & 25 & .57 \\
\hline \multicolumn{4}{|l|}{ Major } & .97 \\
\hline Empyema & 3 & 1 & 4 & \\
\hline Major hemorrhage & 0 & 0 & 0 & \\
\hline Persistent air leak $(>3 d)$ & 3 & 1 & 4 & \\
\hline $\begin{array}{l}\text { Re-expansion pulmonary } \\
\text { edema }\end{array}$ & 2 & 1 & 3 & \\
\hline \multicolumn{4}{|l|}{ Minor } & .97 \\
\hline Subcutaneous emphysema & 2 & 3 & 5 & \\
\hline Operative site infection & 2 & 1 & 3 & \\
\hline Noninfective fever & 3 & 1 & 4 & \\
\hline Minor hemorrhage & 1 & 1 & 2 & \\
\hline
\end{tabular}

There were no deaths attributed to the procedure. Twenty-five complications were encountered in 82 subjects. The major complications included empyema, persistent air leak and re-expansion pulmonary edema, but there was no instance of major bleeding. The minor complications included subcutaneous emphysema, fever, a small amount of bleeding after the biopsy, and operative site infection. The complication rate was not significantly different between the 2 arms (Table 6). Empyema, which necessitated treatment with intravenous antibiotics, occurred in 4 subjects. Four subjects had air leakage lasting $>3 \mathrm{~d}$, which recovered spontaneously. Hypoxia developed in 3 subjects after the procedure along with the appearance of new-onset bilateral lung opacities. The 3 subjects received diagnoses of re-expansion pulmonary edema and were treated with oxygen and supportive therapy. The intercostal tube remained for a mean \pm SD duration of $5.6 \pm 6.6 \mathrm{~d}$, which did not differ between the 2 groups. The subjects were followed up for a median duration of 10 months (range 3-17 months).

\section{Discussion}

In this study, rigid thoracoscopy was found to be superior to semirigid thoracoscopy on an ITT analysis, but the yield was similar if pleural biopsy could be successfully performed. Rigid thoracoscopy could be performed successfully in 3 subjects in whom semirigid thoracoscopy was unsuccessful. Further, no subjects with a successful biopsy in the rigid arm had any failure of diagnosis, whereas a diagnosis of tuberculous pleuritis was missed in 2 subjects in the semirigid arm.

In pleural effusions undiagnosed by thoracocentesis, closed pleural biopsy increases the yield by $\sim 10 \%$ and $40 \%$, respectively, in malignant and tuberculous pleural effusions, whereas the diagnostic yield of thoracoscopy is $\sim 93 \%$ in both malignant and tuberculous pleural effusions. ${ }^{7}$ Hence in many centers including ours a nondiagnostic pleurocentesis is followed by thoracoscopy. Thoracoscopy can be performed using either video-assisted thoracoscopic surgery (VATS) or "medical thoracoscopy." Medical thoracoscopy is performed under local anesthesia and conscious sedation, whereas VATS requires general anesthesia and single-lung ventilation. For diagnostic pleural biopsy, VATS is rarely required because medical thoracoscopy is highly efficacious and cost-effective. The unfamiliarity of the pulmonary physician with the rigid instrument and familiarity with the flexible bronchoscope has led various investigators to attempt thoracoscopy even with a fiberoptic bronchoscope. ${ }^{17-20}$

The semirigid thoracoscope (pleuroscope) has been designed to combine the best feature of the rigid and flexible instruments with a proximal rigid shaft and a distal flexible tip, and can be maneuvered akin to the flexible bronchoscope. However unlike the rigid thoracoscope, the semirigid instrument can be used only for pleural biopsy and usually cannot be used for adhesiolysis. In the only randomized controlled trial reported to date, ${ }^{14}$ the diagnostic accuracy was $100 \%$ and $97.6 \%$, respectively, for rigid and semirigid thoracoscopy. However, in that study, ${ }^{14}$ subjects 
with a lack of pleural space were excluded from the analysis, whereas in our study, an ITT analysis was performed by also including those subjects in whom the procedure was abandoned. In another retrospective study, ${ }^{13}$ the diagnostic yield of the 2 procedures was comparable (rigid thoracoscopy $96.3 \%$ vs semirigid thoracoscopy $92.3 \%$ ), but the procedures were performed by different operators at different hospitals. In both of the previous studies, the majority of the subjects were those with malignant pleural effusion, whereas in our study, only $30 \%$ of subjects constituted those with malignant effusion.

In this study, the pleural space could not be negotiated in 8 cases, and the procedure had to be stopped. Our hospital is the tertiary referral center for a large population ( $\sim 6$ million people), and most of the subjects presented late at our center (mean duration after onset of symptoms $27 \mathrm{~d})$. Many of them were already receiving treatment including antibiotics and/or antituberculosis therapy. In developing countries, differentiating inadequately treated parapneumonic effusions from tuberculous effusions remains a challenge, ${ }^{21}$ and $38 \%$ of subjects in this study belonged to this category. Moreover, $36 \%$ of our subjects ( 32 of 90 subjects) had received a diagnosis of nonspecific inflammation or fibrinous pleuritis based on pleural biopsy results due to the inclusion of subjects with subacute empyemas. Thoracoscopy helped in ruling out tuberculosis, and we could stop antituberculosis therapy in 11 subjects. These reasons might also explain a higher proportion of adhesions encountered during thoracoscopy in our series (59\%) compared with that in previous reports (between 30 and $40 \%)^{22,23}$ and the failure to obtain a pleural biopsy sample. Also, the duration of the postprocedure tube drainage was longer because many of our subjects had tuberculous and parapneumonic effusions, which is in contrast to other reports ${ }^{14}$ where the majority of the subjects had malignant effusions.

The decision to choose semirigid or rigid thoracoscopy depends on the extent of the adhesions found on imaging. Our study suggests that semirigid thoracoscopy is unlikely to help in those with extensive adhesions, and one should directly resort to rigid thoracoscopy or VATS. ${ }^{6}$ Although all the investigations (namely chest radiograph, ultrasound, and chest CT scan) were not performed in every subject in this study, we believe that ultrasound is the best diagnostic modality of the three because it offers real-time images. In a few subjects with no significant adhesions found on ultrasound, we encountered extensive adhesions during thoracoscopy, especially in those subjects with minimal effusions.

The complication rate was similar in the 2 arms. More subjects in the rigid arm had persistent air leak and/or empyema, which was attributed to extensive adhesiolysis. Many of these subjects with adhesions finally received a diagnosis of complicated parapneumonic effusion (10 of the 11 subjects with complicated parapneumonic effusions had adhesions) with higher chances of secondary infection. The requirement of sedative and analgesics was slightly higher with rigid thoracoscopy as the scope is bigger and maneuvering the scope causes greater pain. Also adhesiolysis was performed only with the rigid scope, thus increasing the requirement for these drugs. Rigid thoracoscopy requires a larger port, which results in a bigger scar, whereas the semirigid scope leaves a smaller scar. The operators found it easier to obtain a biopsy sample with the rigid forceps that accompanies the rigid scope. This is in agreement with the experience of other interventional pulmonologists. ${ }^{10,14}$ Despite a larger biopsy sample size with rigid thoracoscopy, the diagnostic yield was similar in the 2 groups, which is in congruity with the findings of Rozman et al. ${ }^{14}$ However, a recent study ${ }^{24}$ does suggest a higher yield of larger biopsy sample size with semirigid thoracoscopy using a diathermic knife.

The presence of nodules on thoracoscopic examination increased the probability of achieving a definite histological diagnosis after biopsy with variably sized nodules increasing the odds of malignancy and uniformly sized nodules increasing the odds for tuberculosis. Also, the finding of diffuse nodules suggests a diagnosis of tuberculosis. It has been previously suggested that the availability of frozen section examinations of pleural biopsy samples during pleuroscopy might enable the endoscopist to decide on whether to proceed to pleurodesis in the same thoracoscopic setting. ${ }^{25}$ When frozen section examination is not available, as is the case in our institution, one might consider proceeding with pleurodesis in subjects where variably sized nodules are seen on thoracoscopic examination. Similarly, antituberculosis therapy can be started in a setting of high tuberculosis prevalence in the presence of diffuse, small-sized nodules.

Finally, our study has a few limitations including the small sample size and the involvement of a single center. Due to the small sample size, there is a possibility of error caused by a higher number of failed pleuroscopies in the semirigid arm. Hence, a larger trial is required to assess the usefulness of the 2 procedures. We did not verify the results of the nondiagnostic thoracoscopy (nonspecific inflammation/fibrinous pleuritis) by using a reference standard of diagnosis such as thoracotomy or VATS, although we did observe these subjects for at least 6 months. The duration of the procedure was longer than has been reported elsewhere. ${ }^{14}$ The reasons for a longer duration were different in the two arms: included performance of adhesiolysis in the rigid arm and difficulty in obtaining pleural biopsy in the semirigid arm. Also the operators included fellows with variable amounts of experience with the instruments, which caused some bias even though the procedures were supervised by one of the consultants. However, this allowed us to compare the performance of the 2 


\section{Thoracoscopy in Undiagnosed Pleural Effusions}

instruments in a real-life situation where multiple operators with variable experience might be performing the procedures.

\section{Conclusions}

In conclusion, the study found a higher diagnostic yield with rigid thoracoscopy on an ITT analysis. The yield was similar wherever a biopsy could be performed with the semirigid device. It may be better to resort to the rigid device if adhesions are present or suspected. Due to the small sample size, a larger study is required to define the usefulness of the 2 procedures and the choice of a particular thoracoscope in different subsets of subjects.

\section{REFERENCES}

1. Loddenkemper R. Thoracoscopy—state of the art. Eur Respir J 1998; 11(1):213-221.

2. Maskell NA, Butland RJ. BTS guidelines for the investigation of a unilateral pleural effusion in adults. Thorax 2003;58(Suppl 2):ii8ii17.

3. Christopher DJ, Peter JV, Cherian AM. Blind pleural biopsy using a Tru-cut needle in moderate to large pleural effusion - an experience. Singapore Med J 1998;39(5):196-199.

4. Poe RH, Israel RH, Utell MJ, Hall WJ, Greenblatt DW, Kallay MC. Sensitivity, specificity, and predictive values of closed pleural biopsy. Arch Intern Med 1984;144(2):325-328.

5. Prakash UB, Reiman HM. Comparison of needle biopsy with cytologic analysis for the evaluation of pleural effusion: analysis of 414 cases. Mayo Clin Proc 1985;60(3):158-164.

6. Lee P, Colt HG. Rigid and semirigid pleuroscopy: the future is bright. Respirology 2005;10(4):418-425.

7. Rahman NM, Ali NJ, Brown G, Chapman SJ, Davies RJ, Downer NJ, et al. Local anaesthetic thoracoscopy: British Thoracic Society Pleural Disease Guideline 2010. Thorax 2010;65(Suppl 2):ii54-ii60.

8. Mootha VK, Agarwal R, Singh N, Aggarwal AN, Gupta D, Jindal SK. Medical thoracoscopy for undiagnosed pleural effusions: experience from a tertiary care hospital in north India. Indian J Chest Dis Allied Sci 2011;53(1):21-24.

9. Lee P, Colt HG. Pleuroscopy in 2013. Clin Chest Med 2013;34(1): $81-91$.

10. McLean AN, Bicknell SR, McAlpine LG, Peacock AJ. Investigation of pleural effusion: an evaluation of the new Olympus LTF semi- flexible thoracofiberscope and comparison with Abram's needle biopsy. Chest 1998;114(1):150-153.

11. Mohan A, Chandra S, Agarwal D, Naik S, Munavvar M. Utility of semirigid thoracoscopy in the diagnosis of pleural effusions: a systematic review. J Bronchology Interv Pulmonol 2010;17(3):195-201.

12. Agarwal R, Aggarwal AN, Gupta D. Diagnostic accuracy and safety of semirigid thoracoscopy in exudative pleural effusions: a metaanalysis. Chest 2013;144(6):1857-1867.

13. Khan MA, Ambalavanan S, Thomson D, Miles J, Munavvar M. A comparison of the diagnostic yield of rigid and semirigid thoracoscopes. J Bronchology Interv Pulmonol 2012;19(2):98-101.

14. Rozman A, Camlek L, Marc-Malovrh M, Triller N, Kern I. Rigid versus semi-rigid thoracoscopy for the diagnosis of pleural disease: a randomized pilot study. Respirology 2013;18(4):704-710.

15. Light RW, Macgregor MI, Luchsinger PC, Ball WC Jr. Pleural effusions: the diagnostic separation of transudates and exudates. Ann Intern Med 1972;77(4):507-513.

16. Colt HG. Thoracoscopy. A prospective study of safety and outcome. Chest 1995;108(2):324-329.

17. Senno A, Moallem S, Quijano ER, Adeyemo A, Clauss RH. Thoracoscopy with the fiberoptic bronchoscope. A simple method in diagnosing pleuropulmonary diseases. J Thorac Cardiovasc Surg 1974; 67(4):606-611.

18. Gwin E, Pierce G, Boggan M, Kerby G, Ruth W. Pleuroscopy and pleural biopsy with the flexible fiberoptic bronchoscope. Chest 1975; 67(5):527-531

19. Robinson GR, 2nd, Gleeson K. Diagnostic flexible fiberoptic pleuroscopy in suspected malignant pleural effusions. Chest 1995;107(2): 424-429.

20. Yokoyama T, Toda R, Tomioka R, Aizawa H. Medical thoracoscopy performed using a flexible bronchoscope inserted through a chest tube under local anesthesia. Diagn Ther Endosc 2009;2009:394817.

21. Ng TH, How SH, Kuan YC, Hasmah H, Norra H, Fauzi AR. Medical thoracoscopy: Pahang experience. Med J Malaysia 2008;63(4):298301.

22. Prabhu VG, Narasimhan R. The role of pleuroscopy in undiagnosed exudative pleural effusion. Lung India 2012;29(2):128-130.

23. Mohan A, Naik S, Naseer R, Boon C, Mills J, Pandey RM, et al. Performance characteristics of semirigid thoracoscopy in pleural effusions of undetermined etiology. J Bronchology Interv Pulmonol 2010;17(4):289-294.

24. Sasada S, Kawahara K, Kusunoki Y, Okamoto N, Iwasaki T, Suzuki $\mathrm{H}$, et al. A new electrocautery pleural biopsy technique using an insulated-tip diathermic knife during semirigid pleuroscopy. Surg Endosc 2009;23(8):1901-1907.

25. Fielding D, Hopkins P, Serisier D. Frozen section of pleural biopsies at medical thoracoscopy assists in correctly identifying benign disease. Respirology 2005;10(5):636-642. 